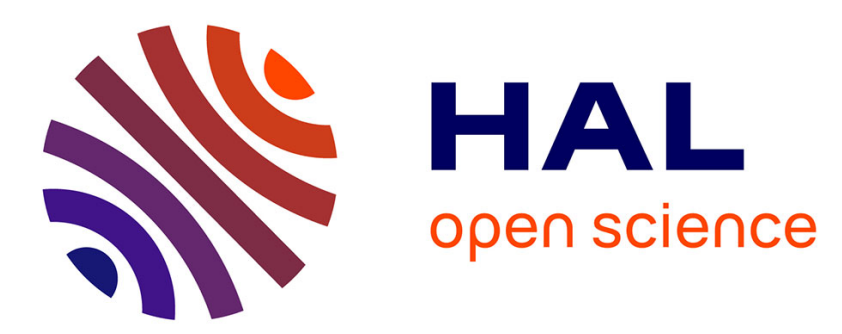

\title{
Disorder in the quasi-one-dimensional conductor monoclinic tantalum trisulfide TaS3
}

\author{
G. Mihaly, N. Housseau, H. Mutka, L. Zuppiroli, J. Pelissier, P. Gressier, A. \\ Meerschaut, J. Rouxel
}

\section{- To cite this version:}

G. Mihaly, N. Housseau, H. Mutka, L. Zuppiroli, J. Pelissier, et al.. Disorder in the quasi-onedimensional conductor monoclinic tantalum trisulfide TaS3. Journal de Physique Lettres, 1981, 42 (12), pp.263-265. 10.1051/jphyslet:019810042012026300 \& jpa-00231923

\section{HAL Id: jpa-00231923 https://hal.science/jpa-00231923}

Submitted on 1 Jan 1981

HAL is a multi-disciplinary open access archive for the deposit and dissemination of scientific research documents, whether they are published or not. The documents may come from teaching and research institutions in France or abroad, or from public or private research centers.
L'archive ouverte pluridisciplinaire HAL, est destinée au dépôt et à la diffusion de documents scientifiques de niveau recherche, publiés ou non, émanant des établissements d'enseignement et de recherche français ou étrangers, des laboratoires publics ou privés. 


\title{
Disorder in the quasi-one-dimensional conductor monoclinic tantalum trisulfide $\operatorname{TaS}_{3}\left({ }^{*}\right)$
}

\author{
G. Mihaly (**), N. Housseau, H. Mutka, L. Zuppiroli \\ Section d'Etude des Solides Irradiés, Centre d'Etudes Nucléaires, 92260 Fontenay-aux-Roses, France
}

\section{J. Pelissier}

Département de Métallurgie, Centre d'Etudes Nucléaires, 38041 Grenoble, France

\author{
P. Gressier, A. Meerschaut and J. Rouxel
}

Laboratoire de Chimie des Solides $\left({ }^{* * *}\right)$, Université de Nantes, 2, rue de la Houssinière, 44702 Nantes, France

(Reçu le 16 mars 1981, accepté le 28 avril 1981)

\begin{abstract}
Résumé. - Nous avons irradié aux neutrons et aux électrons, des monocristaux de trisulfure de tantale $\mathrm{TaS}_{3}$, mesuré leur résistance en fonction de la température avant et après irradiation, et suivi à $7 \mathrm{~K}$ dans un microscope électronique à haute tension l'évolution sous irradiation des diagrammes de microdiffraction électronique. Même à des concentrations de l'ordre de $10^{-3}$ at., les défauts d'irradiation sont capables d'épingler les ondes de densité de charge, d'empêcher leur mise en ordre à basse température et de gommer les transitions de phase des courbes résistance-température. En dépit de tout ceci les propriétés de la phase isolante ne sont guère affectées par l'irradiation et $\mathrm{TaS}_{3}$ apparaît comme le premier conducteur unidimensionnel dans lequel l'épinglage des ondes de densité de charge ne produit aucun changement dans la résistivité à basse température.
\end{abstract}

\begin{abstract}
Single crystals of monoclinic tantalum trisulfide $\mathrm{TaS}_{3}$ have been irradiated with fast electrons and neutrons. Resistivity versus temperature curves have been recorded, before and after irradiation from 30 to $300 \mathrm{~K}$ and electron diffraction patterns have been followed, in situ, during irradiation at $7 \mathrm{~K}$ in a high voltage electron microscope. Irradiation defects even in low concentrations of about $10^{-3}$ have been shown to pin the charge density waves, to prevent their low temperature ordering and to smear out the phase transitions from the resistivity versus temperature curves. In spite of that, the insulating low temperature properties do not disappear. In fact, the monoclinic $\mathrm{TaS}_{3}$ is shown to be the first low dimensional conductor in which the pinning of the charge density waves produces no change in the low temperature resistivity.
\end{abstract}

In several aspects the physical properties of tantalum trisulfide are qualitatively similar to those of the well-known quasi-one-dimensional organic conductors such as TTF-TCNQ and related compounds. Let us briefly mention a few common characteristics : the transport properties are quasi-one-dimensional, the longitudinal conductivity at room temperature being of the order of $100(\Omega . \mathrm{cm})^{-1}$ and the anisotropy of the order of 100 (a measurement performed at Fonte-

(*) This letter is the English version of a Note presented to the Academy of Sciences, 9 March 1981.

(**) Present address : Central Research Institute for Physics, P.O.B. 49, 1525 Budapest.

$(* * *)$ C.N.R.S., LA 279.
nay-aux-Roses gives, more precisely, $\left(\sigma_{\mathrm{b}} / \sigma_{\mathrm{c}}\right)_{300 \mathrm{~K}} \simeq 200$ for monoclinic $\mathrm{TaS}_{3}$ ). In both systems, uncorrelated charge density waves are present at room temperature and appear on electron and X-ray diffraction patterns as diffuse lines [1]. In both systems, charge density waves tend to correlate when the temperature is lowered; their ordering drives one or several phase transitions which can be seen either through transport properties (Fig. 1) or the diffraction patterns (lines condensate into spots). As a result of this common set of properties monoclinic tantalum trisulfide appears to be closer to quasi-one-dimensional organic conductors than other trichalcogenides of the same family such as $\mathrm{NbSe}_{3}$ [2].

Effects of disorder have been demonstrated to be 


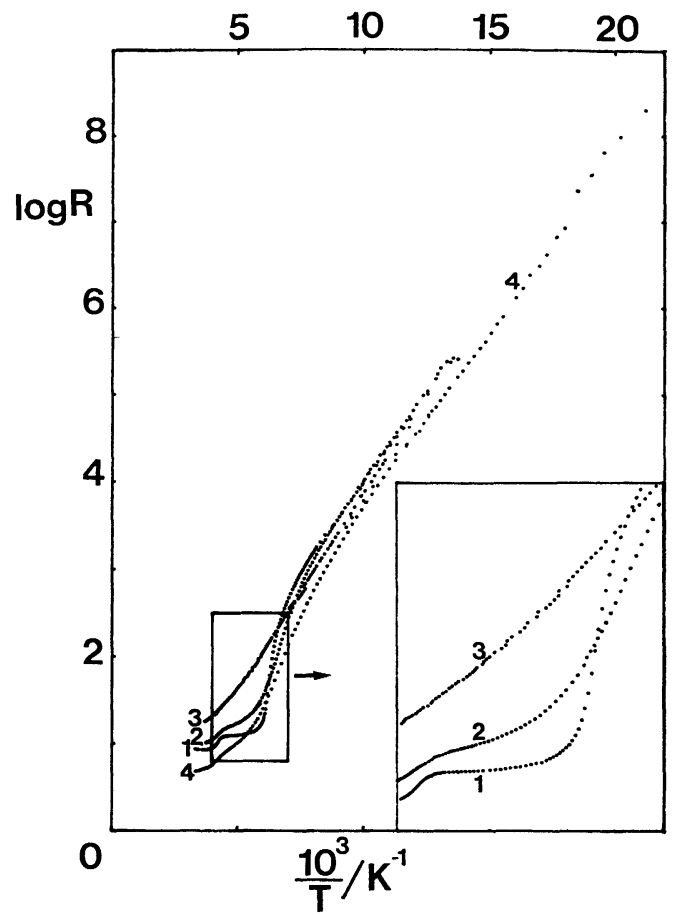

Fig. 1. - Arrhenius plot of the resistance of pure and irradiated single crystals of $\mathrm{TaS}_{3}$. Curve 1 corresponds to a pure sample, curves 2 and 3 to electron irradiated samples at doses of $8 \times 10^{-4}$ d.p.Ta and $8 \times 10^{-3}$ d.p. Ta respectively. Curve 4 corresponds to a neutron irradiated sample at a dose of $10^{-3}$ d.p.Ta. The inset shows details of the phase transitions.

crucial for a clear understanding of the electronic properties of organic metals [3, 4] and Peierls systems $[5,6]$. This is the reason why we decided to disorder $\mathrm{TaS}_{3}$ in a controlled way by irradiation and to study subsequently the electron diffraction patterns and the resistivity of the irradiated samples.

Small needles of $\mathrm{TaS}_{3}$ were produced by the method described in reference [7]. Each crystal was carefully characterized by a Weissenberg $\mathrm{X}$-ray pattern in order to be sure that it was of the monoclinic polytype.

Three crystals were irradiated at $60 \mathrm{~K}$ in the "Vinka " cooling device in the nuclear reactor at Fontenay-aux-Roses and their longitudinal resistivities followed during irradiation as a function of dose, and versus temperature before and after irradiation. The total dose was $6 \times 10^{17} \mathrm{n} / \mathrm{cm}^{2}$ corresponding to a concentration of defects of about $10^{-3}$ d.p.Ta (displacement per tantalum).

Three other crystals were irradiated by the $2.0 \mathrm{MeV}$ electrons of the Van de Graaff accelerator at Fontenayaux-Roses. Resistivity versus temperature curves were recorded after several doses up to $5 \times 10^{19} \mathrm{el} / \mathrm{cm}^{2}$ corresponding to defect concentrations of up to $2 \times 10^{-2}$ d.p.Ta.

Two crystals were irradiated by $1 \mathrm{MeV}$ electrons in the high voltage electron microscope (H.V.E.M.) in Grenoble up to a dose of $1 \%$ d.p.a.Ta. The temperature of the sample, placed in a recently constructed liquid helium cooling holder [10] was $7 \mathrm{~K}$ and micro- diffraction patterns of the sample were recorded in situ during irradiation.

In order to obtain an accurate estimate of the number of atoms displaced by irradiation, an analysis of the damage was performed in the Van de Graaff accelerator. By increasing slowly the energy of the electrons, one can reach and cross three energy limits which correspond to three thresholds : the threshold energy for displacements of sulfur atoms, the displacement threshold for indirect displacements of tantalum by sulfur atoms and finally the threshold for direct displacements of tantalum by the electrons [8]. At temperatures between 60 and $300 \mathrm{~K}$ the damage in the sulfur lattice was found to be inefficient in changing the transport properties of the irradiated crystal. Direct tantalum displacements were found to be the most effective cause of damage and the displacement threshold energy for this process was found to be $16 \pm 1 \mathrm{eV}$ a value very close to that measured in $\mathrm{TaS}_{2}$ [9]. This result explains why one can express the dose scalc in fraction of displaced tantalum (d.p.Ta $=$ displacement per tantalum). We have not yet verified how this estimated dose scale correlates with that obtained from anisotropy measurements which give directly the number of breaks in the conducting chains of irradiated 1-D organic metals [3, 4].

Let now consider the principal results of these irradiation experiments. At $65 \mathrm{~K}$, the resistivity of the pure sample was of the order of $10^{4} \Omega . \mathrm{cm}$ and was ohmic with the currents used $(10 \ldots 100 \mathrm{nA})$. During neutron irradiation at this temperature the resistance was measured in situ with an electrometer. The conductivity of $\mathrm{TaS}_{3}$ did not change within experimental error for defect concentrations of up to $10^{-3} \mathrm{~d}$.p.Ta. After this neutron dose a resistivity versus temperature curve was recorded; the two phase transitions were almost completely smeared out in this curve which exhibited a single activation energy of $80 \mathrm{meV}$. This curve is plotted in figure 1 as $\log _{10} \rho$ versus $1 / T$, together with the resistivity curves of a sample irradiated by $2 \mathrm{MeV}$ electrons.

In the H.V.E.M. in Grenoble the lowest $1 \mathrm{MeV}$ electron flux that we could use was $1.3 \times 10^{16} \mathrm{el} / \mathrm{cm}^{2} . \mathrm{s}$ corresponding to a damage rate of $1.5 \times 10^{-6} \mathrm{~d} . \mathrm{p} . \mathrm{Ta} / \mathrm{s}$. During irradiation, microdiffraction patterns were recorded every two minutes, each photograph requiring an exposure time of one minute. The first photograph of a series is shown in figure $2 a$. The condensated spots of the low temperature charge density wave superstructure are still present in this pattern but together with diffuse lines which do not appear in the unirradiated sample at this temperature [1]. When the defect content is $3.5 \times 10^{-4} \mathrm{~d}$.p. Ta there is no longer a three-dimensional superstructure at $7 \mathrm{~K}$ but only uncorrelated C.D.W. giving rise to diffuse lines very similar to those seen at room temperature in the pure sample. These uncorrelated charge density waves pinned to defects are present up to high irradiation doses as shown in figure $2 b$. Note that because of 


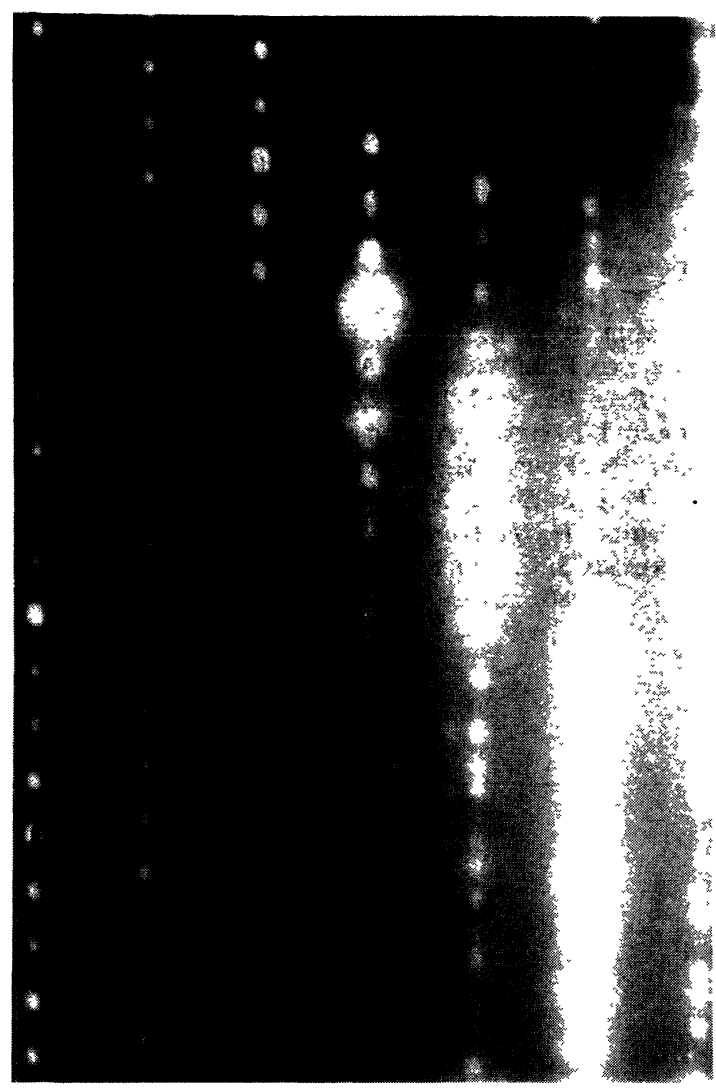

a)

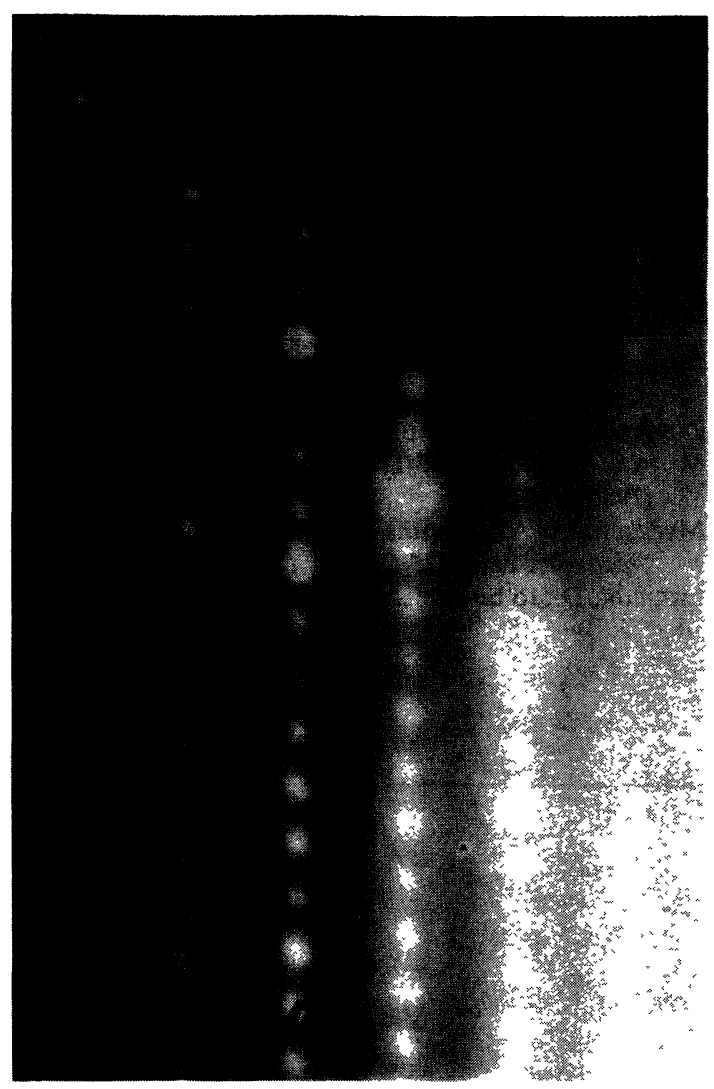

b)

Fig. 2. - Electronic microdiffraction patterns at $7 \mathrm{~K}: a$ ) At a dose of $2 \times 10^{-4}$ d.p.Ta the low temperature superstructure is still partially visible but diffuse lines begin to appear. $b$ ) At $10^{-2}$ d.p.Ta the diffuse lines are still present.

imposed experimental conditions (focusing of the electron beam) the width of the diffuse lines gives no reliable estimate of the correlation length of the lattice distortions.

The pinning of the charge density waves by defects and its effects on the transport properties has been extensively studied in quasi-one-dimensional organic conductors $[3,5,11]$ as well as in quasi-two-dimensional metallic dichalcogenide $1 \mathrm{~T}-\mathrm{TaS}_{2}[9,12,13]$. In all these low temperature insulating systems the disorder has qualitatively the same effects : the random potentials of the defects fix the phases of the charge density waves, and prevent ordering of the C.D.W.'s, and the coherence needed for the complete achievement of the metal to insulator transitions. Hall effect measurements in irradiated $\mathrm{TaS}_{2}[9]$ as well as in a few irradiated organic conductors [14] have shown that the number of carriers in the "insulating phase " increases very quickly with the defect concentration and reaches a value very similar to the room temperature one. Consequently the low temperature conductivity increases in the longitudinal as well as in the transverse directions $[6,4,5]$ and reaches values typical of a metallic phase.

Monoclinic $\mathrm{TaS}_{3}$ is the first low dimensional system in which the pinning of the charge density waves by defects, visible on the diffraction patterns, doesn't produce any change either in the low temperature resistivity value, or in the low temperature activation energy.

To understand this very peculiar property one must consider the origin of the $80 \mathrm{meV}$ activation energy in the " pure " sample. If this energy indicates a real gap related to ordering of the charge density waves, one needs to understand why this gap is not suppressed (at least locally) by defects which should destroy the charge density wave ordering and so sweep away the transitions seen on the resistivity curves.

A small activation energy in a disordered system is very often the sign of not a real gap but of a mobility edge [15], fixed range hopping [16], a system of interrupted strands [3] or metallic particles [17]. In such a picture, one needs to understand why the activation energy and the absolute value of the low temperature conductivity are so independent of the defect concentration in the present system.

New experiments are necessary to understand this particularly exciting behaviour of the quasi-onedimensional conductor, monoclinic $\mathrm{TaS}_{3}$, and they are in progress at Fontenay-aux-Roses. Presently an interpretation based on electron correlation effects and Mott localization seems to be the most realistic explanation of the properties of the low temperature phase of $\mathrm{TaS}_{3}$. 


\section{References}

[1] Roucau, C., Ayrolles, R., Monceau, P., Guemas, L., MeersChaut, A., Rouxel, J., Phys. Status Solidi (a) 62 (1981) 483.

[2] Hodeau, J. L., Marezio, M., Roucau, C., Ayrolles, R., Meerschaut, A., Rouxel, J., Monceau, P., J. Phys. C (Sol. State Phys.) 11 (1978) 4117.

[3] Zuppiroli, L., Bouffard, S., BechgaARd, K., Hilti, B., MAYer, C. W., Phys. Rev. B. 22 (1980) 6035.

[4] Mihaly, G., Bouffard, S., Zuppiroli, L., BechgaArd, K., J. Physique 41 (1980) 1495.

[5] ZuPPIRoli, L., Bouffard, S., J. Physique 41 (1980) 291.

[6] Mutka, H., Lesueur, D., Zuppiroli, L., Radiat. Eff. 45 (1980) 219.

[7] Meerschaut, A., Guemas, L., Rouxel, J., C. R. Hebd. Séan. Acad. Sci. Paris 215 (1980).

[8] Lesueur, D., to be published in Philos. Mag. (1981).
[9] MutKa, H., Note CEA-N-2170.

MutKa, H., Zuppiroli, L., Molinie, P., Bourgoin, J. C., to be published in Phys. Rev. B (1981).

[10] Pelissier, J., Cortial, H., Disdier, F. Compte Rendu D.M.G., Centre d'Etudes Nucléaires de Grenoble, 19 (1980).

[11] Bouffard, S., Chipaux, A., Jerome, D., Solid State Commun. 37 (1981) 405.

[12] McMillan, W. L., Phys. Rev. B 12 (1975) 1187.

[13] Di Salvo, F. J., Wilson, J. A., Bagley, B. G., Wasczak, J. V., Phys. Rev. B 12 (1975) 2220.

[14] Forro, L., JANOSSY, A., ZUPPIROLI, L., to be published (1981).

[15] Mott, N., PePper, M., Poltt, S., Wallis, R. M., Adkins, C. J., Proc. R. Soc. A 345 (1975) 169.

[16] OVERHOF, H., Festkörperprobleme XVI (1976)

[17] Garland, J. C., Gully, W. J., Tanner, D. B., Phys. Rev. B. 22 (1980) 507. 